\title{
An Examination of Learning Profiles in Physical Education
}

\author{
Bo Shen \\ Wayne State University \\ Ang Chen \\ University of Maryland at College Park
}

\begin{abstract}
Using the model of domain learning as a theoretical framework, the study was designed to examine the extent to which learners' initial learning profiles based on previously acquired knowledge, learning strategy application, and interest-based motivation were distinctive in learning softball. Participants were 177 sixth-graders from three middle schools. A hierarchical cluster analysis was conducted to determine what kinds of learning profiles would result from the interactions among prior knowledge, learning strategies, and interest. The results revealed that individual learners could be classified into subgroups with distinctive learning characteristics. It is supported that learning in physical education is a progressive process that involves both cognitive and affective dimensions. An effective physical education curriculum should address both knowledge and skill acquisition and motivation simultaneously.
\end{abstract}

Key Words: prior knowledge, learning strategy, interest

Research in education has supported the notion that the interaction of cognitive involvement and motivation directly influences individual choice and willingness to engage in learning tasks and achievement (Pintrich, Marx, \& Boyle, 1993). From an integrated perspective, Alexander, Jetton, and Kulikowich (1995) proposed the model of domain learning to explain the multidimensional interplay of prior knowledge, learning strategies, and interest-based motivation during learning in a subject-matter domain. The model delineates learning as a progression from a lower stage to a higher stage and dependent upon the level of interaction of prior knowledge, learning strategies, and interest in a subject-matter domain. Learning in the physical activity domain has been postulated with similar progressive characteristics that, however, have rarely been investigated from an integrated perspective. The purpose of this study was to examine the model of domain learning by

Shen is with the Department of Kinesiology, Health, and Sport Study, Wayne State University, Detroit, MI 48202, and Chen is with the Department of Kinesiology at University of Maryland-College Park, College Park, MD 20742. 
identifying middle school physical education learners' distinctive characteristics and constructing their initial learning profiles related to prior knowledge, learning strategies, and interest.

\section{The Model of Domain Learning}

A subject-matter domain is disciplinary knowledge institutionalized for the purpose of education (Alexander, 1997). Learning tasks within a domain often share common features and underlying processes. In a subject-matter domain, prior knowledge is broadly described as the knowledge that an individual possesses relative to the specific domain (Alexander, Sperl, Buehl, \& Fives, 2004). Learning strategies are mental operations or techniques that learners use to solve problems or to enhance achievement (Alexander \& Jetton, 2000). Strategies are goal-directed procedures for the completion of a specific task by performing, assessing, and regulating learning behavior.

Learners are expected to put forth effort to learn new knowledge and skills through applying relevant prior knowledge and adopting effective strategies. But the effort is in large part dependent upon the extent to which the learner is motivated to learn in the particular domain. As a primary motivator, interest has been found to play a powerful role in motivating students to learn (Alexander et al., 1995). Two types of interest have been conceptualized in the model of domain learning: individual interest and situational interest. Individual interest is defined as an individual's relatively enduring predisposition of preference to certain objects, events, and activities. It is based on increased knowledge, positive emotions, and increased value in these activities (Hidi, 2000). Situational interest, on the other hand, is generated by certain stimulus characteristics in an activity and tends to be shared among individuals. Situational interest is based on a short, tentative relationship between a person and a particular activity at a given moment (Reeve, 1996). Findings in education (Hidi, 2000) and physical education (Chen \& Darst, 2001) have supported the idea that interest can attract learners to particular learning tasks, increase engagement time on tasks, improve information storage, and enhance achievement.

A salient characteristic of the model of domain learning is its explicit recognition of learning to be a domain-specific process. Knowledge, learning strategies, and interest are dynamically interrelated components in this process that interact to influence learning outcomes. The interactive relationship is domain unique (Alexander et al., 2004). In other words, a pattern of interaction among the variables observed in learning a particular knowledge/content may or may not be observable in another. The uniqueness, however, resides in an identifiable common process of learning characterized as progressing from the acclimated or naïve stage, to the competent stage, and potentially, to the proficiency or expertise learning stage.

At the acclimation learning stage, the learner has limited knowledge/skill. Efforts are directed toward constructing a framework of domain knowledge. During this stage, deep-seated individual interest is quite low (Hidi, 2000). Learners are often concerned with getting through the task. The primary motivator is situational interest that attracts the learner to the learning task, helps the learner to focus on the task, and elicits continuous effort and energy. 
At the competency stage, the learner is beginning to master important domain knowledge and skills. Although learners may continue to be attracted by situational interest in a task, individual interest begins to replace situational interest as a major motivator while situational interest is being internalized into individual interest. Effective strategies begin to emerge and become stable in the learner's knowledge structure and help learning effectiveness by tuning and personalizing pieces of new information. Effective learning strategies become the major learning tool for the learner. A competent learner can demonstrate greater comprehension and better performance of the domain knowledge than does a learner in the previous stage (Alexander \& Jetton, 2000).

At the proficiency stage, the learner becomes an expert in applying effective learning strategies for greater learning effectiveness. Individual interest becomes the sole motivator for the learner. The attainment of proficiency calls for the learner to set goals and pursue them primarily by themselves. With increased quantity and quality of domain knowledge, the proficient learner experiences deep comprehension with ease (Alexander \& Jetton, 2000).

\section{Research on the Model of Domain Learning and the Purpose of the Study}

The multidimensional, multistage model of domain learning has been studied mostly with samples of college students and conducted in classroom setting. For example, Alexander and Murphy (1998) examined college students' development of knowledge, learning strategies, and interest over an academic semester in learning educational psychology. Their findings support that integrating cognitive processes with motivation is a dominant predictor of learning achievement. The students who began the semester with high individual interest, strategic processing, and with a moderate level of prior domain knowledge were more likely to achieve at a higher level than others. Learning was influenced by the integrated function of prior knowledge, learning strategies, and interest-rather than one factor alone. Similarly, consistent results have been found with learners in immunology (Alexander et al., 1995) and special education (Alexander et al., 2004). However, the model of domain learning and its functions in $\mathrm{K}-12$ physical education have not been investigated.

Physical education is a subject-matter domain in which students are expected to learn kinesiological knowledge, physical skills, and skill themes about human movement patterns (Allison, Pissanos, Turner, \& Law, 2000). Learning in physical education has rarely been delineated and understood from a multidimensional perspective (Solmon, 2003). The role of prior knowledge/skill, learning strategies, and motivation are often studied in isolation from each other with distinct theoretical frameworks (Chen, 2001). Little is known about learner differences in patterns of interactions among knowledge, learning strategies, and interest. The nature of the relations among the cognitive and motivational variables and their interactive effects on learning remains unstudied.

Acquisition of knowledge and skills in physical education is accomplished gradually and characterized by several learning stages (Schmidt \& Wrisberg, 2000), similar to those described in the model of domain learning. Physical education 
studies have revealed that prior knowledge (Silverman, Subramaniam, \& Woods, 1998), learning strategies (Solmon \& Lee, 1996), and interest (Chen \& Shen, 2004) can directly influence students' learning process. The learning characteristics described in the model of domain learning make it possible that the model of domain learning may provide a meaningful, unifying theoretical framework to accommodate knowledge, learning strategies, and interest for a comprehensive and in-depth understanding of learning progression in physical education.

Using the model of domain learning as a theoretical framework, this study was designed to examine the extent to which learners' initial learning profiles based on prior knowledge, learning strategy application, and interest-based motivation were distinctive in learning softball. In addition, because physical education is a discipline with unique content specificity in which learners are not only expected to learn knowledge and skills, but also to learn in a physically active manner (Center for Disease Control and Prevention, 1996), we also explored the possibility to profile learner characteristics in relation to in-class physical activity at the beginning of the unit.

This study is one of the few attempts to explore the interplay among prior knowledge, learning strategies, and interest in physical education from an integrated theoretical perspective. As Tobias (1994) suggested, educators should move beyond the question of whether or not cognitive and motivational learning factors are related, and should start to focus on the more important, albeit more complex issues of how they relate and how their interactive nature influences learning. The identification of individual learning profiles may enhance our understanding of the interactive function between cognitive involvement and motivation on learning in physical education.

\section{Methods}

\section{The Research Settings}

Considering the purpose of this study, it was decided that the study should be conducted in physical education programs, where the learning of physical skills, movement concepts, and movement principles was the primary goal of instruction. Specifically, both concepts and skills should be equally emphasized in physical education. In addition, the physical education curriculum should be in line with national and state standards (National Association for Sport and Physical Education [NASPE], 2004). Tasks and activities in class must be learning-oriented.

Three schools from two counties in the Baltimore and Washington metropolitan area were selected from a pool of potential participating schools. The schools enrolled a total of approximately 2,300 students in the sixth, seventh, and eighth grades at the time of the study. The majority of students came from the middle socioeconomic background and represented a range of ethnic groups: $81.5 \% \mathrm{Cau}-$ casian, $10.3 \%$ African, $7 \%$ Asian, and 1.2\% Latino Americans.

All three schools used a 90-min block, 3-day (A-, B-, C-day) rotating schedule. Students had a physical education class on every third day. Students from the same grade had physical education in the same period. The three participating teachers (one male and two females, one from each school) were full-time, certified physical 
educators. Their teaching experience levels ranged from 5 to 25 years. The teachers were all active members of the American Alliance for Health, Physical Education, Recreation and Dance (AAHPERD).

\section{Participants}

Student participants in this study were 202 sixth-graders selected from nine regular physical education classes in the three schools (three classes in each school). Parental consent forms and student assent forms were received ahead of data collection. Among the 202 students, 25 were unable to complete all the measures owing to absences and other reasons. The final sample consisted of 177 students.

We chose sixth-graders because as first-year middle school students, they are usually experiencing a physical education curriculum that is different from what they had in elementary school. The possible confounding of prior knowledge with grade-related learning content could be minimized. Also, because sixth-grade students have acquired an initial understanding of the value of using learning strategies, they begin to actively use strategies in learning and are capable of expressing their thinking clearly (Paris \& Lindauer, 1982). Our anecdotal observations and interviews with the students support this notion.

\section{Content}

Softball was chosen as the content for the study for two reasons. First, softball is a "thinking-oriented" physical activity (Kneer \& McCord, 1994). It involves both cognitive and physical tasks in order to achieve the learning goals. Second, softball is a physical activity to which the sixth-grade students might have had various exposures outside physical education classes. Therefore, the participants might have been at different learning stages where their different degrees of individual interest, skill, and knowledge could be manifested.

The softball units as new content to all the sixth-graders were taught in spring 2004. It was 4 weeks long in all three schools. The class size in the three schools ranged from 27 to 32 students. Major learning tasks at the first lesson of the unit centered on concepts (e.g., basic rules, tactical concepts) and basic skills (e.g., throwing and catching). The concepts and skills were learned through skill practices in groups. The participating teachers were familiar with their students and used both direct and problem-solving instructional methods in teaching.

\section{Variables and Measures}

Prior Knowledge. Before the unit began, students' prior knowledge in softball was assessed using (1) a knowledge test that measured students' conceptual understanding of softball and (2) teacher subjective rating on skills. In physical education research, teacher rating of students' skills has been considered an efficient way to measure students' skill levels (Martinek, 1988; Silverman et al., 1998).

Knowledge was measured using a 14-item multiple-choice test. All items in this test were framed on content from the county's physical education curriculum guide for sixth-graders. As illustrated below, the purpose of this test is to assess students' cognitive knowledge of softball. 
Question: A right-handed pitcher will step with the foot as he/she release the ball toward home.
(a) right
(b) left (correct answer)
(c) either

The items in the multiple-choice test were dichotomously scored as correct (1 point) or incorrect ( 0 point). The maximum score of this test was 14 points.

In order to examine content validity of the softball knowledge test, experienced physical education teachers who did not participate in this study $(N=4$, three females and one male, with 10 to 15 years experience of teaching softball) were asked to rate content representativeness $(1=$ not representative at all, $6=$ representative very much) and the language appropriateness for the sixth-graders $(1=$ not appropriate at all, $6=$ appropriate very much $)$ of each item. The range of ratings for each item was from 4 to 6 . The mean scores for the content representativeness and language appropriateness were 5.0 and 5.8, respectively, suggesting acceptable validity.

Students' skill was evaluated using teacher subjective rating. The participating teachers were asked to rate each student's overall softball skill level in their own class twice on a 7-point scale $(1=$ lowest, $7=$ highest $)$ based on their perceptions after the first day and the second day of the unit. The intrarater coefficients over the 2 -day period were $83 \%, 85 \%$, and $91 \%$ for the three teachers, indicating their ratings were acceptable.

It is worthwhile to notice that although teachers' rating to determine skill level has been used in previous physical education studies, the validity of this measure has not been established. We considered it as a limitation of this study. In future research design, a validated and objective measure should be applied to better assess students' skill performance.

Learning Strategies. Learning strategies were measured using the five-item strategy subscale of Cognitive Process Questionnaire in Physical Education (CPQPE; Solmon \& Lee, 1997). Each item asked students to identify themselves with a described learning behavior and to rate on a 5-point scale, with 1 meaning "not like me at all" and 5 "very much like me."

Solmon and Lee (1997) reported an internal consistency coefficient (Cronbach's $\alpha$ ) of .66 for the learning strategies subscale for middle school students. In this study, the version of CPQPE was modified with softball replacing physical education to situate the items in the specific topic knowledge of this study. The five items in strategy subscale include, "When the teacher explained a skill, I practiced the skill in my mind," "I talked to myself during practice to help me do better," "I tried to practice skills I learned in softball," "When I was practicing a skill, I tried to think how it is like something I already know," and "I tried to go over right away to perform the skill I learned in softball in my mind."

Individual Interest. Individual interest in softball was measured using Physical Activity Interest Survey (Chen \& Darst, 2002). The survey instrument is designed to rate students' individual interest in various physical activities using a 7-point scale $(7=$ highest interest, $1=$ lowest interest $)$. In order to decrease self-determined reference frame for rating, the respondent is asked to identify an activity (any activity) $\mathrm{he} / \mathrm{she}$ is most interested in and give a rating score of 7 as a reference to compare 
and rate other activities. According to Tobias (1994), this measurement context strengthens the possibility that the students interpret the rating scale consistently to better maintain the internal validity of the measure. The survey in this study included 18 physical activities offered in the physical education curriculum.

Situational Interest. Situational interest was measured using a 24-item Situational Interest Scale (Chen, Darst, \& Pangrazi, 1999), which contains a Total Interest subscale and five source dimensions. Students were guided to rate on a 5-point scale ( 5 = strongly agree, 1 = strongly disagree) in terms of specific learning tasks they were experiencing. According to Chen et al. (1999), the construct validity of Situational Interest Scale was established for middle school students using a factor analytical approach with exploratory and confirmatory factor loadings ranging from .50 to .90 . The reliability coefficient was .95 for the Total Interest subscale. In this study, we used the sum score of the four Total Interest items (20 points) to represent the direct measure of situational interest. These items included, "What we were learning today looked fun to me," "It was fun for me to try what we were learning," "What we were learning was interesting for me to do," and "What we were learning attracted me to participate."

In-Class Physical Activity. Students' in-class physical activity level was measured using Yamax SW-200 Digi-Walker pedometers (Tokyo, Japan), which recorded total steps taken during the lesson. All Digi-Walker pedometers were checked using a walking test and a manual shake test (Vincent \& Sidman, 2003) before distributing them to the participants.

\section{Data Collection and Analyses}

All the data were collected during regular physical education classes in the three schools. The individual interest survey and knowledge test were administered before the softball unit began. To diminish a potential confounding effect of initial learning profiles with new acquisition of knowledge and skills over the unit, it was decided that situational interest data, learning strategy data, and Digi-Walker data were collected at the end of the first softball lesson.

Pearson product-moment correlations were conducted to investigate general interrelations among different learning variables. To identify groups of learners sharing similar responses on the learning constructs, a hierarchical cluster analysis was conducted to determine what kinds of initial learning profiles would result from the interactions among prior knowledge, learning strategies, and interest. The aim of cluster analysis was to identify homogeneous groups or clusters based on their shared characteristics. It has been suggested that using cluster analysis can strengthen an individual's multifaceted learning pattern and avoid using one single variable's aggregated mean score to stand for the whole set of learning features (Salomon, 1991).

To examine within-subject response profiles, we used Ward's minimum variance hierarchical clustering technique to conduct the cluster analysis (Lattin, Carroll, \& Green, 2004). Of many cluster analysis approaches, Ward's hierarchical clustering procedure is known to be able to generate groups with the least within-group variance and to maintain effectively the structure of data. Although the Ward's cluster analysis tends to create clusters of small size, its efficiency to 
recover underlying learning structure in the education domain has been proven by many cluster-based studies (e.g., Alexander \& Murphy, 1998; Alexander et al., 2004). In this method, it is usually that the two closest clusters join together in a sequential and nonoverlapping way at each combining stage. The number of meaningful clusters is determined by identifying the largest distances between cluster groups. Last, a multivariate analysis of variance (MANOVA) was used to test for differences between clusters on the learning variables as well as for differences between the clusters on physical activity level.

\section{Results}

\section{Preliminary Analysis}

The internal consistency reliability coefficients (Cronbach's $\alpha$ ) were .70 for the learning strategy data, .89 for the situational interest data, and .71 for the knowledge test. The $\alpha$ coefficients indicated an acceptable level of reliability for these measures. The indices of skewness for all measures ranged from -.82 to .87 , indicating that the assumption of data distribution normality was not violated. The assumption of homogeneity of covariance (Box $M$ ) of knowledge, interests, and learning strategies was $52.73, F(42,78,460)=1.19, p=1.84$, indicating that the equal covariance assumption was not violated. Overall, the results showed that the data met the assumptions for the statistical analyses chosen.

A MANOVA was conducted to examine school effect on students' responses. That is, whether students' responses differed simply because they were in different schools. The results revealed that there were no significant overall differences among schools with these variables, Wilks's $\Lambda=.93, F(12,336)=2.365, p=$ .097. Therefore, the data from the three schools were combined into one data set for further analyses.

Table 1 shows the descriptive statistics for the whole sample and the intercorrelations between the variables. The participants had intermediate scores on knowledge test, teachers' skill rating, and individual interest in softball. Their application of learning strategies at the first lesson was also in an intermediate level. High situational interest score at the first lesson indicated that the participants recognized that the class was situationally interesting. As expected, statistically significant correlations were revealed between knowledge, teachers' skill rating, and individual interest. The situational interest was found to correlate with the learning strategies and individual interest. There were correlations between the learning strategies and individual interest and between the learning strategies and knowledge test score. However, the correlation of the learning strategies with teachers' skill rating was not found. Steps taken at the first lesson were not found to correlate with any other learning variable.

\section{Cluster Analysis}

To address the heterogeneity in different learning profiles, we conducted cluster analyses using the five learning variables of prior knowledge, teachers' skill rating, individual interest, the situational interest, and the learning strategies to detect 


\section{Table 1 Descriptive Statistics for the Whole Sample and the Inter- correlations Between the Variables $(N=177)$}

\begin{tabular}{lccccccc}
\hline Variable & Maximum & Total: $\boldsymbol{M}$ (SD) & $\mathbf{2}$ & $\mathbf{3}$ & $\mathbf{4}$ & $\mathbf{5}$ & $\mathbf{6}$ \\
\hline 1. Individual interest & 7 & $4.29(1.94)$ & $.52^{* *}$ & $.32^{* *}$ & $.34^{* *}$ & $.16^{*}$ & -.15 \\
2. Knowledge test & 14 & $8.89(2.54)$ & - & $.45^{* *}$ & $.22^{* *}$ & .09 & -.01 \\
3. Teachers' skill rating & 7 & $3.84(1.45)$ & & - & .10 & .04 & .09 \\
4. Learning strategies & 25 & $15.88(4.62)$ & & - & $.46^{* *}$ & .05 \\
5. Situational interest & 20 & $15.06(3.60)$ & & & - & -.05 \\
6. Steps & - & $1.895(712)$ & & & & - \\
\hline${ }^{*} p .05$ (2-tailed), ${ }^{* *} p<.01$ (2-tailed). & & & & & &
\end{tabular}

emergent clusters. Teachers' skill rating was included in the analysis because student learning in physical education consists of both knowledge and skills.

To begin Ward's hierarchical clustering procedure, a distance matrix among the variables was computed with the estimation from measures of association. Clusteranalysis results were summarized in a graphical depiction that corresponded to a hierarchical tree generated by the iterative sequence. This method has been shown to be effective in the validation of set clusters in previous studies. In our analysis, two noticeable gaps between identified clusters were found, indicating that the interactive features of the learning variables were distinctive between the clusters. In terms of the result, we classified the learners into three cluster groups.

In order to ensure the validity of the emergent clusters, two additional analyses were conducted to confirm the solutions obtained. First, according to a Lattin et al. (2004) suggestion, a nonhierarchical analysis: $k$-means clustering method was used to verify the result. This method has been shown to be effective in the validation of set clusters in previous studies (i.e., Wang \& Biddle, 2001). In the $k$-means clustering, the initial centroid values were classified as the seed point for the analyses using random iteration. The final centroid values and the cluster sizes were compared to those obtained from the hierarchical method. The results in this study confirmed the three-cluster solution and the profiles corresponded well with those obtained from the original analysis.

Second, according to Alexander et al., (2004), a discriminant analysis was conducted to examine whether or not the identified clusters had the right configuration of learning variables in terms of the assumption in the model of domain learning. Discriminant analysis is a statistical method that is often used to find combinations of quantitative variables that maximally discriminate between groups (Lattin et al., 2004). Using knowledge, teachers' skill rating, individual interest, situational interest, and learning strategies as independents, the discriminant analysis showed that $95.0 \%$ cluster membership was predicted correctly. Specifically, there were $97.8 \%$, $92.0 \%$, and $97.6 \%$ accuracy rates for Clusters 1, 2, and 3, respectively. Overall, the verifications support the three emergent clusters solution. Table 2 summarizes the descriptive statistics of the three clusters. 
Table 2 Cluster Means and Standard Deviations for the ThreeCluster Solution

\begin{tabular}{lcccccc}
\hline Variable & \multicolumn{2}{c}{$\begin{array}{c}\text { Cluster } 1 \\
(n=45)\end{array}$} & \multicolumn{2}{c}{$\begin{array}{c}\text { Cluster } 2 \\
(\boldsymbol{n}=90)\end{array}$} & \multicolumn{2}{c}{$\begin{array}{c}\text { Cluster } 3 \\
(\boldsymbol{n}=42)\end{array}$} \\
\cline { 2 - 7 } & $\boldsymbol{M}$ & $\boldsymbol{S D}$ & $\boldsymbol{M}$ & $\boldsymbol{S D}$ & $\boldsymbol{M}$ & $\boldsymbol{S D}$ \\
\hline Individual interest & $1.56_{\mathrm{c}}$ & .744 & $4.68_{\mathrm{b}}$ & .98 & $6.40_{\mathrm{a}}$ & .66 \\
Knowledge test & $7.28_{\mathrm{c}}$ & 1.46 & $8.34_{\mathrm{b}}$ & 2.28 & $11.81_{\mathrm{a}}$ & 1.35 \\
Skill evaluation & $3.20_{\mathrm{b}}$ & 1.19 & $3.52_{\mathrm{b}}$ & 1.29 & $5.19_{\mathrm{a}}$ & 1.15 \\
Learning strategies & $13.94_{\mathrm{b}}$ & 4.39 & $16.11_{\mathrm{a}}$ & 4.39 & $17.45_{\mathrm{a}}$ & 4.70 \\
Situational interest & 14.13 & 3.76 & 15.28 & 3.80 & 15.56 & 2.81 \\
Steps & 2,035 & 654 & 1,846 & 737 & 1,850 & 713 \\
\hline
\end{tabular}

Note. Subscript letters that differ in each row denote which group means are significantly different from one another $(\mathrm{a}=.05)$.

\section{Profiles of Cluster Groups}

As shown in Table 2, three clusters were identified from the hierarchical clustering technique. There were 45 students in the Cluster 1. Generally, what characterized this group were their low levels of knowledge, teachers' skill rating, individual interest, and the learning strategies. Cluster 2, by comparison, consisted of 90 students with relatively high knowledge, teachers' skill rating, individual interest, and the learning strategies. Cluster 3 included 42 students with highest scores in the learning variables.

To understand the differences among the clusters, we conducted a multivariate analysis of variance (MANOVA) with the cluster groups as the independent variable and knowledge, teachers' skill rating, individual interest, the situational interest, the learning strategies, and the steps taken at the first lesson as the dependent variables. Results of the MANOVA indicated significant overall differences among cluster groups, Wilks's $\Lambda=.32, F(12,338)=51.78, p<.01$. Univariate follow-ups revealed that the cluster groups were significantly different on knowledge $F(2,174)=68.98$, $p<.01, \eta^{2}=.44$; individual interest $F(2,174)=364.37, p<.01, \eta^{2}=.81$; teachers' skill rating $F(2,174)=34.04, p<.01, \eta^{2}=.28$; and the learning strategies $F(2$, $174)=6.99, p<.01, \eta^{2}=.10$. However, neither the situational interest $F(2,174)=$ $2.09, p>.05$ nor the steps $F(2,174)=1.17, p>.05$ were found to be significantly different among the three clusters, indicating that the learners, regardless of their learning stages, had a similar recognition of situational interest and physical activity level at the beginning of the softball unit.

To obtain a better understanding of the significant univariate effects among the three cluster groups, we conducted a series of multiple comparisons with Fisher's LSD procedure to control familywise Type-I error rates. Based on the post hoc 
analyses, all cluster groups were significantly different from one another with respect to prior knowledge and individual interest in softball. Learners in Cluster 3 had a significantly higher score in teachers' skill rating than did all other clusters, whereas the difference between Clusters 1 and 2 was not significant. Learners in Cluster 1 had a significantly lower score in the application of learning strategies than did all other clusters, whereas the difference between Clusters 2 and 3 was not significant.

\section{Discussion}

The purpose of the study was to identify individuals' initial learning profiles in learning softball. The model of domain learning was used as a theoretical framework. According to this model, learning in a specific knowledge domain is a staged process characterized by various, dynamic interactions among prior knowledge, learning strategies, and interest. In this study, we measured learners' prior knowledge, learning strategies, individual and situational interest when they were learning softball in middle-school physical education. The data were analyzed using hierarchical clustering analysis and MANOVA to reveal the interrelations among the variables. The results showed that individual learners could be identified into subgroups with distinctive learning profiles in terms of their prior knowledge, learning strategies, and interest at the beginning of the softball unit.

\section{Classification of Initial Learning Profiles}

According to the model of domain learning, learning in a domain should develop gradually from an acclimation stage to a competency stage, and eventually to a proficiency stage. A proficient learner would show a high level of knowledge, deep-strategic processing of information, and high individual interest in the topics in the knowledge domain. It can be assumed that K-12 learners have not achieved at the proficiency or expertise level in any knowledge domains taught to them (Alexander, 1997). A similar assumption could be made for the learners in this study, and the learners were expected to be at either acclimation or competent level. On the basis of the cluster differences and composition of the clusters, we referred to Clusters 1, 2, and 3 as the early-acclimation, late-acclimation, and competence groups, respectively. These labels suggest the developmental positions within the model of domain learning.

\section{Prior Knowledge and Individual Interest Differences Among the Profiles}

As would be assumed from the model of domain learning, learners' knowledge level in a particular domain is usually consistent with the level of their individual interest. Students at different learning stages may differ in terms of their knowledge level and individual interest. In the study, this assumption was supported. The learners at the early-acclimation stage (in Cluster 1) demonstrated the least prior knowledge both on the knowledge test and teachers' skill rating. In comparison with other clusters, this cluster was also characterized by the lowest reported individual interest in softball. The low knowledge accompanied with low individual interest 
may represent a typical fragmented and incoherent learning profile of acclimated learners (Alexander et al., 1995). Meanwhile, the late-acclimation learners in Cluster 2 demonstrated significantly higher levels of both prior knowledge and individual interest. That is, learners in this cluster performed better on the knowledge test and reported greater individual interest in softball than the learners in early-acclimation cluster.

However, although individuals in the late-acclimation cluster were more knowledgeable than those in the early-acclimation cluster, their knowledge and interest were still moderate. The means on these measures did not approach the high score value. In addition, there was no significant difference between early-acclimation and late-acclimation clusters in terms of teachers' skill rating. Those in the lateacclimation cluster showed relatively low teachers' skill rating score despite their relatively higher knowledge and individual interest scores. This phenomenon supports the notion that beginning learners' psychomotor development may not always grow simultaneously with their cognitive understanding of the physical activities (Thomas \& Thomas, 1994).

Learners in the competence cluster significantly differ from those in other clusters in prior knowledge and individual interest. They are more knowledgeable and skillful. Further, they reported the highest individual interest among the three clusters. The finding supports that the competent learners' knowledge, skill, and individual interest might have grown together (Alexander et al., 2004). They had a more coherent and richer learning profile than the learners at the acclimation group to begin with in learning softball.

\section{Learning Process Differences Among the Profiles}

Prior knowledge and individual interest can directly influence the learning process. Learners at different learning stages can demonstrate different learning characteristics. The function of prior knowledge and individual interest in learning can be manifested in the application of learning strategies and the recognition of situational interest (Alao \& Guthrie, 1999). When the learners develop from the acclimation learning stage to the competency stage, they are expected to apply more learning strategies and show more interest in class.

The result in the MANOVA supported the influence of knowledge and individual interest on learning strategies. The significant difference between early-acclimation cluster and competence cluster in the application of learning strategies suggests that learners who were knowledgeable and interested in the learning content were more likely to use learning strategies to understand main ideas and concepts than those who were not at the beginning of the unit. The competent learners' cognitive involvement during learning was effortful and planful (Alexander et al., 1995). For the learners at the early-acclimation learning stage, their low score on the application of strategies indicated that they could not use learning strategies effectively at the beginning. Most of their cognitive efforts were directed toward attending to the skill rather than using learning strategies to reconstruct the knowledge structure (Schmidt \& Wrisberg, 2000).

There was no significant difference between late-acclimation cluster and competency cluster in the application of learning strategies. Specifically, the learners at both clusters applied learning strategies moderately. The learners at the competency 
cluster did not apply more learning strategies than the learners in the late-acclimation cluster at the first lesson.

A plausible explanation might result from the learning context. Solmon and Lee (1996) argued that the role of learning strategy on high skill and knowledge learners in physical education might depend upon the learning situation. The level of difficulty in the learning task may influence their application of learning strategies. When the content does not provide optimal challenge for the high skill and knowledge learners, learning strategies may not be applied as much as expected during the learning. As a unit for middle school students, the learning tasks at the beginning were introductory in nature and could be viewed by the competent learners as of little challenge. Their moderate ratings on the application of strategies support this explanation.

Situational interest results from the recognition of appealing features associated with a specific learning task (Mitchell, 1993) and can be a significant and viable motivator to facilitate new knowledge learning (Hidi, 2000). It is assumed that learners with high prior knowledge and individual interest in an activity may be more cognizant about situational interest and its effect than those with low prior knowledge and individual interest (Chen \& Darst, 2001). However, this assumption was not supported by the result in MANOVA. There were no significant differences among the three clusters. The students in the three clusters all demonstrated a relatively high situational interest at the first lesson.

The low individual interest but the relatively high situational interest shown in the early-acclimation cluster may indicate that acclimated learners can be motivated by situational interest to the learning tasks. The result supports the model of domain learning in that, at the acclimation learning stage, situational interest is a primary motivator for learners to be attracted to learning tasks. It can be reasoned that in a highly situationally interesting learning environment, situational interest may override the unmotivational effect of low individual interest (Shen, Chen, Scrabis, \& Tolley, 2003).

The similar high situational interest was found for the learners at the late-acclimation and competence clusters. The difference, however, is that for these learners, prior individual interest played an equally important role as situational interest did in influencing learning. Evidently, at the late-acclimation and competence learning stages, individual interest began to replace situational interest as a major motivator. The learners, nevertheless, continued to be motivated by situational interest. It can be speculated that the late-acclimation and competent learners are capable of internalizing situational interest into a personally meaningful motivator (Alexander, 1997). Their high individual interest might help enhance the motivation effect of situational interest associated with learning tasks.

\section{Learning Profiles and In-Class Physical Activity}

In physical education, learners are expected to be physically active at a moderateto-vigorous physiological intensity level to receive health benefits from physical activities and to facilitate knowledge acquisition (NASPE, 2004). Because learning in physical education is often accomplished through physical engagement, we hypothesized that learners' performance profiles might associate with their in-class physical activity level in some way. However, the hypothesized relationships were 
absent in the data. Physical activity level at the first lesson reflected through the steps was not found to be different among the three clusters. Learners at different clusters had similar steps, suggesting that individual learners' initial learning profiles did not connect with their in-class physical activity at the beginning of the unit directly.

This disconnection might contribute to the specificity of softball learning. Silverman et al. (1998) argued that high skill and knowledge learners are likely to practice with the intensity appropriate for the activity. It is possible that the learners at the competency learning stage might practice at a physiologically efficient state that was sufficient for them to perform well in softball, a low physically intense activity. For the acclimated learners, learning to play softball demands them to acquire highly cognitive understanding of the game, skills, and, more critically, the timing of using appropriate skills. It is likely that for this group of learners, constructing the tactics cognitively became a learning focus more important than becoming fully physically engaged in physical practices. In addition, their low skill level might also prevent them from fully engaging in the physical aspect of the practice. Along with the evidence in other studies showing that the number of steps taken in the class did not associate with learning achievements in different physical education units (e.g., Shen et al., 2003; Shen \& Chen, in press), the study argued that using in-class physical activity level measures (i.e., pedometers) may not be sufficient to reflect students' learning engagement in physical education. A systematic observation study on learners' learning behavior is needed for further understanding this issue.

\section{Conclusion}

In summary, this study as an initial exploration offers support for the assumption of the model of domain learning in physical education. By examining students' prior knowledge, interests, learning strategies, and their interactions, the findings reiterate that learning in physical education is a progressive process that involves both cognitive and affective dimensions. It is suggested that an effective physical education curriculum should address both knowledge and skill acquisition and motivation simultaneously. Physical educators should understand that each student in physical education manifests a different learning profile in terms of the interactions of prior knowledge, learning strategy, and interest. Individual students' differences in physical education should be identified, appreciated, and instructionally addressed during their learning process (Alexander \& Jetton, 2000). In future studies, researchers may need to investigate the transforming process of learning profiles from a longitudinal perspective so that physical educators can better conceptualize and carry out their roles on students learning in physical education.

\section{References}

Alao, S., \& Guthrie, J.T. (1999). Predicting conceptual understanding with cognitive and motivational variables. Journal of Educational Research, 92, 243-253.

Alexander, P.A. (1997). Mapping the multidimensional nature of domain learning: The interplay of cognitive, motivational, and strategic forces. In M.L. Maehr \& P.R. Pintrich (Eds.), Advances in motivation and achievement (Vol. 10, pp. 213-250). Greenwich, CT: JAIPress. 
Alexander, P.A., \& Jetton, T.L. (2000). Learning from text: A multidimensional and developmental perspective. In M.L. Kamil, P.B. Mosenthal, P.D. Pearson, \& R. Barr (Eds.), Handbook of reading research: Vol. III (pp. 285-310). Mahwah, NJ: Lawrence Erlbaum Associates.

Alexander, P.A., Jetton, T.L., \& Kulikowich, J.M. (1995). Interrelationship of knowledge, interest, and recall: Assessing a model of domain learning. Journal of Educational Psychology, 87, 559-575.

Alexander, P.A., \& Murphy, P.K. (1998). Profiling the differences in students' knowledge, interest, and strategic processing. Journal of Educational Psychology, 90, 435-447.

Alexander, P.A., Sperl, C.T., Buehl, M.M., \& Fives, H. (2004). Modeling domain learning: Profiles from the field of special education. Journal of Educational Psychology, 96, 545-557.

Allison, P.C., Pissanos, B.W., Turner, A.P., \& Law, D.R. (2000). Preservice physical educators' epistemologies of skillfulness. Journal of Teaching in Physical Education, 19, 141-161.

Center for Disease Control and Prevention. (1996). Physical activity and health: A report of the Surgeon General executive summary. Atlanta, GA: Author.

Chen, A. (2001). A theoretical conceptualization for motivation research in physical education: An integrated perspective. Quest, 53, 35-58.

Chen, A., \& Darst, P.W. (2001). Situational interest in physical education: A function of learning task design. Research Quarterly for Exercise and Sport, 72, 150-164.

Chen, A., \& Darst, P.W. (2002). Individual and situational interest: The role of gender and skill. Contemporary Educational Psychology, 27, 250-269.

Chen, A., \& Shen, B. (2004). A web of achieving in physical education: Goals, interest, outside-school activity and learning. Learning and Individual Differences, 14, 169-182.

Chen, A., Darst, P.W., \& Pangrazi, R.P. (1999). What constitutes situational interest? Validating a construct in physical education. Measurement in Physical Education and Exercise Science, 3, 157-180.

Hidi, S. (2000). An interest researcher's perspective: The effects of intrinsic and extrinsic factors on motivation. In C. Sansone \& J.M. Harackiewicz (Eds.), Intrinsic and extrinsic motivation: The search for optimal motivation and performance (pp. 309-339). San Diego, CA: Academic Press.

Kneer, M.E., \& McCord, C.L. (1994). Softball: Slow and fast pitch. Sport and Fitness Series. New York: WCB/McGraw-Hill.

Lattin, J., Carroll, J.D., \& Green, P.E. (2004). Analyzing Multivariate Data. Belmont CA: Thomson Brooks/Cole.

Martinek, T.J. (1988). Confirmation of a teacher expectancy model: Student perceptions and causal attribution of teaching behaviors. Research Quarterly for Exercise and Sports, 59, 118-126.

Mitchell, M. (1993). Situational interest: Its multifaceted structure in the secondary school mathematics classroom. Journal of Educational Psychology, 85, 424-436.

National Association for Sport and Physical Education (NASPE). (2004). Moving into the future: National standards for physical education (2nd ed.). Reston, VA: Author.

Paris, S.G., \& Lindauer, B.K. (1982). The development of cognitive skills during childhood. In B. Wolman (Ed.), Handbook of developmental psychology. Englewood Cliffs, NJ: Prentice-Hall.

Pintrich, P.R., Marx, R.W., \& Boyle, R.A. (1993). Beyond cold conceptual change: The role of motivational beliefs and classroom contextual factors in the process of conceptual change. Review of Educational Research, 63, 167-199.

Reeve, J. (1996). Motivating others: Nurturing inner motivational resources. Needham Heights, MA: Allyn \& Bacon.

Salomon, G. (1991). Transcending the qualitative-quantitative debate: The analytic and systemic approach to educational research. Educational Psychologist, 20, 10-18. 
Schmidt, R.A., \& Wrisberg, C.A. (2000). Motor learning and performance. Champaign, IL: Human Kinetics.

Shen, B., \& Chen, A. (in press). Examining the interrelations among knowledge, interests, and learning strategies. Journal of Teaching in Physical Education.

Shen, B., Chen, A., Scrabis, K.A., \& Tolley, H. (2003). Gender and interest-based motivation in learning dance. Journal of Teaching in Physical Education, 22, 396-410.

Silverman, S., Subramaniam, P., \& Woods, A.M. (1998). Task structures, student practice, and skill in physical education. Journal of Educational Research, 91, 298-306.

Solmon, M.A., \& Lee, A.M. (1996). Entry characteristics, practice variables, and cognition: Student mediation of instruction. Journal of Teaching in Physical Education, 15, $136-150$

Solmon, M.A., \& Lee, A.M. (1997). Development of an instrument to assess cognitive processes in physical education classes. Research Quarterly for Exercise and Sport, $68,152-160$.

Solmon, M.A. (2003). Student issues in physical education classes: Attitudes, cognition, and Motivation. In S.J. Silverman \& C.D. Ennis (2nd ed.), Student learning in physical education (pp. 147-163). Champaign, IL: Human Kinetics.

Thomas, K.T., \& Thomas, J.R. (1994). Developing expertise in sport: The relation of knowledge and performance. International Journal of Sport Psychology, 25, 295-312.

Tobias, S. (1994). Interest, prior knowledge, and learning. Review of Educational Research, 64, 37-54.

Vincent, S.D., \& Sidman, C.L. (2003). Determining measurement error in digital pedometers. Measurement in Physical Education and Exercise Science, 7, 19-24.

Wang, C.K., \& Biddle, S.J.H. (2001). Young people's motivational profiles in physical activity: A cluster analysis. Journal of Sport and Exercise Psychology, 23, 1-22. 